\title{
Zimbabwean Students' Perception of Chinese Sounds
}

\author{
Guo Fuliang', Herbert Mushangwe ${ }^{2}$ \\ ${ }^{1}$ College of International Exchange \& Education, Hebei University, Baoding, China \\ ${ }^{2}$ Hebei University, Department of Arts, Baoding, China
}

Email address:

htsungy@yahoo.co.uk (Herbert Mushangwe)

\section{To cite this article:}

Guo Fuliang, Herbert Mushangwe. Zimbabwean Students' Perception of Chinese Sounds. International Journal of Language and Linguistics. Vol. 3, No. 2, 2015, pp. 102-109. doi: 10.11648/j.ij11.20150302.18

\begin{abstract}
The present survey seeks to find out Zimbabwean student's perception of Chinese sounds. The survey was carried out in 8 different schools in Harare, the capital city of Zimbabwe. 23 Chinese words with different initials representing all the consonants in Chinese language were used for the survey. During the survey Chinese words were read to students who had never studied Chinese and the students were asked to write down what they hear using Latin letters. The results of the survey shows that Zimbabwean students in Harare have either English influenced perception or Shona influenced perception. However, there were some instances where random pattern was observed, this could be due to the uniqueness of the given Chinese sounds. We concluded that when teaching Chinese or any other foreign languages a pre-survey is required in order to establish the prevailing influential language. In Zimbabwe any local language at any given place can be more influential in terms of shaping students' perception towards the target language.
\end{abstract}

Keywords: Sound Perception, Chinese Language, Zimbabwe, Second Language Learning

\section{Introduction}

Acquisition of foreign language's sound system relies much on the learner's ability to distinguish the sounds and learning mappings between meaning and phonetic forms (Pajak, Sarah, \& Roger 2012; Brown 2000). This ability to distinguish sounds and associating meaning with given sounds brings us to the concept of perception. According to the definition given on Wikipedia (2015) perception (from the Latin perceptio, percipio) is the organization, identification, and interpretation of sensory information in order to represent and understand the environment. In simple terms, as defined by the Merriam-Webster online dictionary, perception refers to the ability to understand or notice something easily.

Perception is a broad concept which is normally classified under the heading of "Gestalt" in modern psychology. Gestalt theorists argue that the whole is greater than the sum of its parts (Käfer 1982; Fitzek 2008; Fitzek \& Salber 1996). Using this line of argument, perception depends on the human mind and it considers objects in their entirety. We can therefore argue that, when learners of a foreign language perceive a foreign sound they perceive it in its entirety rather than its parts. This is the reason why we considered a survey which involves spellings of words instead of individual consonants and vowels. Sounds in their smallest forms are meaningless until they are grouped to have distinct meaning, thus the ability to perceive a sound is important only when the perceived sound can be associated with specific meaning.

Brown (1997) suggests that second language learners' perceptual abilities are constrained by phonological features. According to Brown (ibid) if the learner's first language lacks certain features needed to differentiate target language's phonological contrast; the learner will be unable to perceive the contrast. Sound perception is therefore not independent of the prevailing languages. Mother tongue, including its writing system can shape how local people perceive foreign language's sounds. For instance when Chinese people encounter foreign sounds they perceive these sounds in terms of the Chinese characters where a single character denotes a meaning. Since Chinese words are basically single morphemes they find it difficult to imagine a multisyllabic word thus they reduce the loanwords into disyllabic or trisyllabic words with partial transliteration. Good perception of sounds is important in second language learning, thus Brown (2000: 7) states that, "successful acquisition of phonological representations requires accurate perception of phonemic contrasts in the input". In light of the above importance of perception in determining acquisition of foreign language's sound system, the present research therefore seeks to find out Zimbabwean student's perception of Chinese 
sounds. This research is necessitated by the fact that Zimbabwe is a multi-lingual country.

\section{Background}

This research was motivated by the researcher's observation that when foreigners in China write or pronounce foreign words, the majority of Chinese people normally use almost similar Chinese characters to represent these foreign sounds. For instance, when the researcher introduces his name to Chinese native speaker they will perceive the name "Herbert" ['heəbət] as 海博[xaipot ] and not 何蓓提[xebeiti]which could be the closest Chinese transliteration. From this observation the researcher felt that the dominant language and its writing system in a given environment directly affect students' perception of foreign language's sounds. Therefore, there is need to know the language which influences learners' perception in a multi-lingual environment. Based on the above observation, the researcher hypothesized that the fact that in China, Chinese language which uses characters is the dominant language which does not compete with any other local language in terms of daily usage thus native speakers of Chinese language basically uses Chinese language as their source of reference when confronted with any new sounds. On the other hand, in a multi-lingual environment the situation is obviously more complex.

In Zimbabwe there are approximately over 16 languages, 3 of which are more influential; English is the official language while Ndebele and Shona are national languages (Ndlovu 2013). Given the fact that Zimbabwe is a multi-lingual country, it is therefore difficult to determine the language which affects Zimbabwean students when acquiring any other foreign language like Chinese which was recently introduced in Zimbabwe. Though Zimbabwe is a multilingual country English, Shona and Ndebele are the dominant languages, and for some people (especially those living in the rural areas) tend to speak Shona or Ndebele more than they speak English, while those who grew up in the low density suburbs in big cities tend to speak English more than Shona or Ndebele. There is also the middle group which speaks both local languages and English equally the same. Our survey was carried out in Harare which is the capital city of Zimbabwe with complex mixture of students from rural areas and those who grew up in the cities. The aim of the survey is to find out the extent to various languages in this multi-lingual environment influences Zimbabwean students' perception of Chinese sounds.

Chinese language known as Mandarin or 'Putonghua' which means standard language for China mainland belongs to the Sino-Tibetan language family. It is one of the widely spoken languages in the world. Based on the 1.5 billion average population of China, it can be argued that one fifth of the world population speaks Chinese. This estimate is below the actual number of Chinese speakers because Chinese language is also national language for countries such as Singapore, Malaysia and other small countries in Asia.

However, though Chinese is widely spoken in Asia, it is one of the rarest languages in Africa. In Zimbabwe, Chinese was introduced in 2007 at the University of Zimbabwe. Within the past few years a number of students in the department of Arts as well as other departments started registering for Chinese courses either as optional courses or mandatory course for their degree programmes. It is predictable that soon or later Chinese language might become one of the most influential languages in Zimbabwe and Africa at large.

Chinese language differs from both African languages and European languages mainly because it is a tonal language and it is transcribed using characters. Mushangwe $(2012,2013,2014)$ attempted a comparative analysis between Chinese and Shona (Zimbabwean language), in his comparative researches it was found that though Shona is also a tonal language but the effect of Chinese tones is evident on almost all Chinese words while for Shona only selected words are affected by tonal differences. Also, Shona vowels seem to be simpler compared to Chinese vowels. However, Shona has more inventories of consonants which are more that 60 compared to the 23 Chinese consonants (also known as initials). Due to the differences between Chinese and African languages, it is normal that the majority of Africans feel like Chinese sounds are strange sounds.

Considering these differences between Chinese and other languages, as well as the Zimbabwe's multi-lingual environment, there are possibilities of anomalies in terms of Zimbabwean students' perception of Chinese sounds. In order to find out the language which influences sound perception for students in a multi-lingual environment of Zimbabwe Chinese sounds we therefore carried out a survey using Chinese words as a case study. In the following section an attempt will be made to review some of the researches which laid foundation for the present research.

\section{Literature Review}

The present study is not a pioneer study in the field of students' perception of second language. There are a number of researches which describe the students' perception of sounds for foreign language. Some of these researches include researches by Gong, Cooke \& Lecumberri (2011); these researchers used quantitative method to analyze native speakers of Mandarin's perception of English consonants. The researchers used 30 native Chinese listeners with moderate English competence for the survey; the results showed that native speakers of Chinese's perception of English were directly affected by orthography. This means that Chinese characters directly influence Chinese speakers' perception of foreign language's sounds.

In another separate research, Zhu (2014) also discussed Chinese native speakers' perception of English native speaker's speech. The results of the survey showed that the participants produced $[\theta]$ better than they perceived it. This therefore suggests that there are instances when perception of target language's sounds does not directly reflect learner's actual pronunciation. Perception of sounds normally affects second language learners' listening capabilities, though to some extent poor perception of second language's sounds would cause challenges in pronunciation.

Brown (2000) is one of the researchers who also contributed 
a lot to the topic under discussion. In the chapter "The interrelation between speech perception and phonological acquisition from infant to adult", Brown argued that one aspect that differentiates between children's ability to acquire first language and adults' ability to acquire second language is the fact that adults come to the task of acquiring a second language with knowledge of another language. Brown's research offers a critical assessment of the adult and children's perception of language speech during acquisition.

Mayo, Florentine \& Buus (1997) once did a research to determine the impact of age to perception of second-language speech. Their research concluded that monolinguals and early bilinguals have better perception compared to late bilinguals. Their findings indicate that learning a second language at an early age is beneficial to perception of second language speech.

Past researchers in the field of acquisition and perception seem to put more emphasis on perception of single sounds such as [k] or [m], (see researches by Brown 1997; Hall 2003). The present research differs from previous researches in the sense that attempts will be made to treat sounds in their entirety. This is based on the gestalt theory which states that the whole is greater than the sum of its parts. The main argument is that; when measuring language learners' perception of second language's sound system, more emphasis should be placed on the whole (that is words or phrases) rather than on single meaningless phonemes such as $[\mathrm{x}]$ or $[\mathrm{p}]$. Below is our hypothesis.

\section{Hypothesis}

This paper is based on the hypothesis that; second language learners perceive sounds as a whole and they base their understanding of the foreign language's sounds on what they know already; however this knowledge is not limited to mother tongue only. We argue that learners' knowledge of other languages might also have an impact on learners' perception of target language's sounds. Therefore, perception of foreign language's sounds can change as learner's knowledge of new sounds increase. In an article posted on the internet by Sandra (2013) titled "Perception is Reality Marketing" the following picture was used to show how perception differs depending on one's standing position.

\section{It is really confusing!!!}

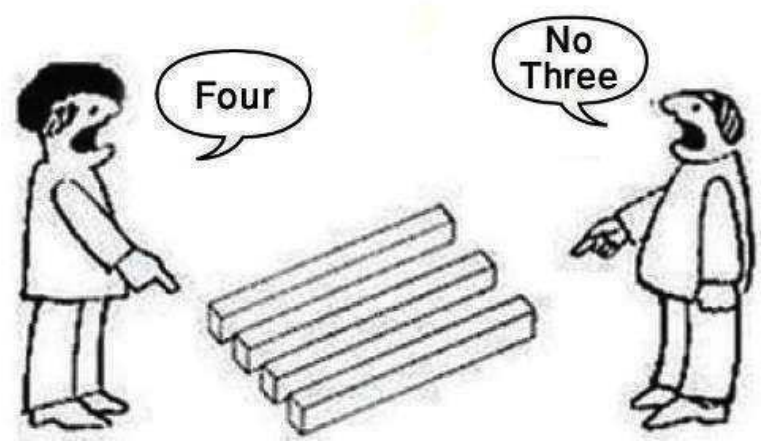

Figure 1. Perception differences depending on one's position
Based on the picture above, perception depends on where one stands, it is how people see and understand something depending on what they believe or feel, thus, it might differ from one person (or culture, society etc) to another. In other words, one's awareness of something builds from what he/she knows already and his/her own interpretation. Therefore in this article we argue that; in learning a foreign language, learners' perception of sound differs from one student to another depending on the sounds they know already.

According to Todorovic (2008), when people look at the world, they usually perceive complex scenes composed of many groups of objects on some background, with the objects themselves consisting of parts, which may be composed of smaller parts. Following Todorovic's argument, we therefore hypothesize that; when language learners perceive sounds from other languages they perceive them as bigger parts which can be broken into smaller parts. Hence we can argue that, phrases and words are the bigger parts of sounds which attract learners' attention most. This does not mean that the smaller parts of sounds, such as the phonemes, are not important. Our argument in this paper is that the bigger parts (phrases and words) do attract learners more, and learners' perception depends much on how these bigger parts appeal to them.

Todorovic (2008) mentioned that there are laws of perception (also known as the Gestalt principles); some of these principles which will be adopted for this research include the following: principle of similarity, principle of pragnanz and principle of proximity. The principle of similarity states that, the human mind quickly identifies objects which are similar. Based on this principle, we hypothesize that in learning a foreign language, language learners draw conclusions based on the similarities between foreign language's sounds and what they know already. The principle of pragnanz states that people usually simplify reality as much as possible. This explains why native speakers of Chinese language would simplify the word "Herbert" into "haibote", to the native speakers of Chinese this is the simple version. Hence, based on this principle we also expect a lot of simplification of Chinese sounds by Zimbabwean students. The principle of proximity states that elements tend to be perceived as aggregated into groups if they are near each other. Thus, instead of testing Zimbabwean students' perception of single sounds we will use complete words; that is 'grouped sounds'.

In this research we will therefore attempt to analyze these principles as they apply to perception of Chinese sounds by Zimbabwean students. The main aim is to find out whether the mentioned principles of perception (principle of simplicity, principle of pragnanz and principle of proximity) cause Zimbabwean students to perceive Chinese sounds more as English or as Zimbabwean local languages.

\section{Methodology}

This paper is an experimental study on perception towards Chinese sounds by Zimbabwean students. The exercise was done with 302 students from 4 primary schools and 4 High schools in the city of Harare (the capital city of Zimbabwe). The selection of the schools was done at random based on the 
availability of the students. This was because in some schools, the teachers were not willing to allow the researcher to interact with the students. Details for the participants of the survey (such as age range and number of participants per class) are given on appendix 1.23 Chinese words with initials representing all the different Chinese consonants were used for this survey. A detailed list of the words which were used for this survey is available on appendix 2 . Words were used instead of single phonetic units because we believe that the whole is greater than its parts. Due to limited resources, the researcher could not afford to visit schools outside the city of Harare. The area chosen is dominated by English and Shona speakers. So there were no Ndebele speakers in schools which were visited.

The research was done through spelling exercises which were given to students under examination conditions. During the spelling exercise, 23 Chinese words were read several times to students who had never studied Chinese and the students were asked to write down what they hear using Latin letters. Students' answers were analyzed and grouped according to their nearness to any of the local languages.

\section{Procedures, Results and Analysis of the Perception Test}

The survey took a period of a month during the month of June 2012, this involved request for research permission from the Ministry of Education as well as the actual visits to the target schools. Schools were chosen at random in 3 districts which are Harare North, Harare central and Harare South. During the visits, students were engaged in 30 minutes of spelling test where the researcher would read Chinese words 5 to 10 times and the students would write the words they hear either as known Shona/English words or following Shona/English spelling system. For instance, for the Chinese word 菜 cai [ts^ai] some students would either write it as an
English word "tie" or as an English spelling "thai", while some students would write it as a Shona word "tsvai" (ideophone for completed) or as a Shona spelling (with no known mean) "tsayi".

Results of the spelling test were grouped mainly into 2 categories which are; Shona-influenced perception and English-influenced perception. This grouping was based on the spellings' nearness to English or Shona. For those spellings which were neither close to English or Shona, they were regarded as complete errors and were grouped as random or others. For detailed variations of spellings for Chinese words which were observed during this survey see appendix 3 .

In order to calculate the average percentage of English or Shona's influence to perception of Chinese sounds we grouped all students' spellings according to the spellings' closeness to either Shona or English. Then we counted the words per each class. As an example, for Allan Wilson High school for the word 爸爸, 9 students wrote this word in English as "papa" while 13 students wrote it as "baba" as it is written in Shona. In order to calculate the average of English's influence for this school we divided 9 by the total number of students in the class which is 22 and multiplied by 100; thus in this class $41 \%$ of the students were influenced by English in their perception of the Chinese word 爸爸. After the basic calculations per word we went on to calculate the average influence of either English or Shona per each class. We added up the percentages per each class and divide by 23 (the number of words used in the survey).

Results for primary and high schools were separated because there were clear differences in terms of percentages of students influenced by English and those influenced by Shona. As shown on bar graph 1 below, primary school students were mainly influenced by Shona in their transcription of Chinese words while the majority of high school students were mainly influenced by English.

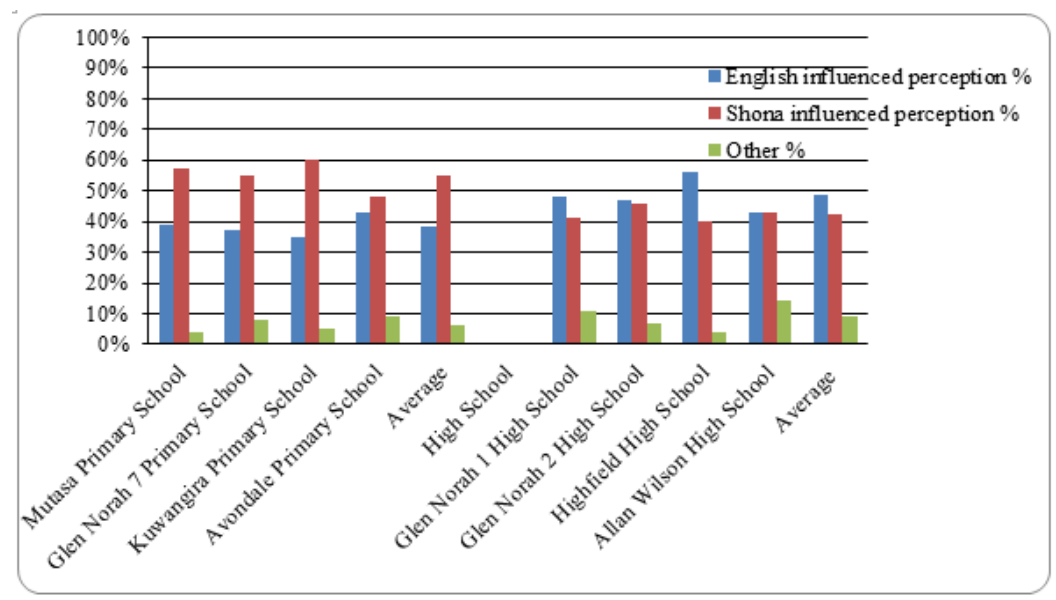

Bar graph 1. Percentages of Students Influenced by English or Shona

Based on this bar graph we can also conclude that though the impact of both Shona and English on Zimbabwean students' perception seems to be equal, however some results show that primary school students seem to depend more on Shona knowledge in their perception of foreign sounds. For instance for the Chinese word 租 zu all the primary school students used Shona spellings to transcribe this word while some high school students transcribed it in English as /due, drew or draw/. The same trend was also observed on the word 才(cai). Despite the fact that this word generally sounds like a 
Shona word, there was a higher percentage of high school students who transcribed it as an English word "tie" or English spelling "thai". As shown on appendix 4, Kuwangira Primary school had the highest Shona-influenced perception of Chinese sounds $(60 \%)$ while Glen Norah 7 Primary School came second with 55\%. Among the Primary schools, Avondale Primary School had the highest level of English-influenced perception of Chinese sounds which was at $43 \%$, however the Shona-influenced percentage was still slightly above that of Shona. The overall results showed that for Primary school students, Shona-influenced perception of Chinese sounds is 55\%, which is higher than English-influenced perception which is $38.5 \%$.

Note that the other $6.5 \%$ is classified as other, representing those spellings which were classified as random since they could neither fit under English or Shona. The random category is of interest because it could represent human creativity based on known aspects. This category could be due to noise or the fact that students did not hear well. Random spellings appeared, more on those words which are neither close to English nor Shona. However, the majority of these words are errors, for example; instead of transcribing 发 fa with almost related Shona or English words some few students would write words such as "ba" or "pa". We noted that a number of students would write spellings which are neither related to English, Shona or any other local language, in an attempt to transcribe the Chinese sounds which they have never heard of. This implies that Zimbabwean students learning Chinese language are likely to be able to accommodate any new sounds which they never have heard of before.

For high schools, Highfields high school recorded a higher level of English-influenced perception, which was as high as $56 \%$ while for Allan Wilson High school both Shona and English had equal influence on students' perception of Chinese sounds. The average percentages however showed that, for High school students, English-influenced perception was higher than Shona-influenced perception see appendix 4 for specific percentages per each school.

The analysis of the students' spellings also revealed that some students can easily associate certain Chinese words with what they know already. This entails that if teachers do such a survey with new students who will be learning Chinese for the first time, it will be possible to predict students' possible errors due to mother tongue transfer. Based on these observations which show that the influence of Shona to Primary school students' perception of Chinese sounds is higher than that of English, while for all high school students the influence of English to students' perception is slightly higher than that of Shona, we can therefore conclude that for Zimbabwean students; the more they learn English words the more their perception for other sounds is likely to be affected by English. However, we argue that Shona and English are both potentially influential to Zimbabwean students' perception of foreign language's sounds. The above observation also entails that age directly affect second language learners' perception of foreign sounds.

\section{Impact of Principles of Perception to Students' Perception of Chinese Sounds}

As already mentioned in our hypothesis, this research seeks to analyze the applicability of the 3 principles of perception as applied to Zimbabwean students' perception of Chinese sounds. As noted from the spelling variations on appendix 3, the spellings of Chinese words as written by Zimbabwean students vary depending on their nearness to the language of influence as shown in the following diagram.

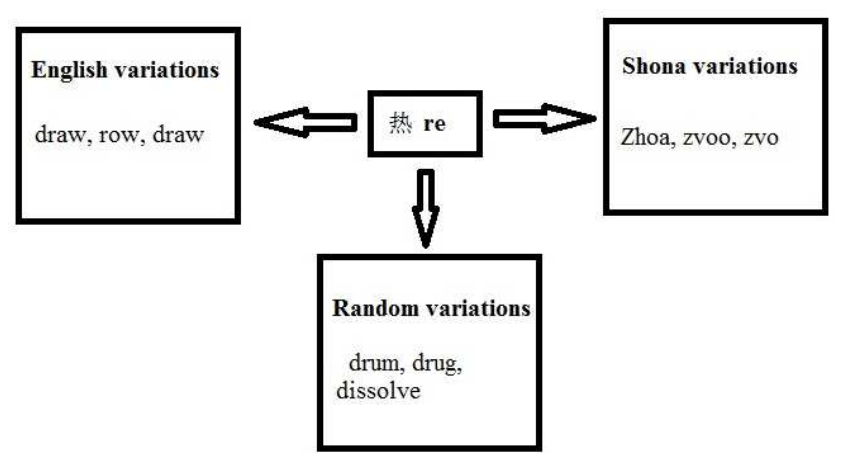

Figure 2. Perceptional differences of the Chinese word 热(re)

This diagram shows that Zimbabwean students use either Shona or English in transcribing Chinese words. One might want to know what really determined the choice of words in transcribing these Chinese words. The choice of the words might seem random or confusing thus people might question; why would the Chinese word 热 re [ ] vary like this, where some students would feel like it sounds like an English sound: draw [dro:], while others feel like it sounds like a Shona sound zvoo [ oo]. These variations can be explained based on the principles of perception which are principle of similarity, principle of pragnanz and principle of proximity.

Earlier on we mentioned that the principle of similarity states that the human mind quickly identifies objects which are similar. The moment learners hear a foreign sound they quickly identify words which seem to be similar to the sound they hear. In this case, students tend to identify the similarities between the initial consonants. For instance for the Chinese word 要 (yao), 租 (zu) and 需要 (xuyao) some students wrote the following words:

i) English variation of 要[jao]: yah [jal], yell[jel], yahoo ['jahu] and yea[jei].

Shona variation of 要[jao]: yawo [jawo], ya-a [ja-a]

ii) English variation of 租 [tsu]: due [dju:], drew [dru:], draw [dro:]

Shona variation of 租 [tsu]: dzu [dz u, dzu-u $\left[\begin{array}{ll}d z & u-u\end{array}\right]$

iii) English variation of 需要 [ ${ }^{\circ}$ ujao]: seeyou [si: ju:], soya [soja], suo[suo], sual [sual]

Shona variation of 需要 [ ${ }^{\circ}$ ujao]: shuyawo [ $\left.\Varangle u j a w o\right]$, suyawo [sujawo], suyao [sujao], suya [suja], suwao [suwao]

In the above examples the Chinese words 要, 租 and 需要 transcribed as [jao], [tsu] and [ ${ }^{\circ}$ ujao] respectively, are perceived differently depending on the language that appeals 
most to the perceiver for that given word at the time of spelling writing. Learners draw similarities which are independent of each other, this is the reason why there are many variations of the same word. We observed that influence of English and Shona to Zimbabwean students' perception of Chinese sounds cannot be strictly identified with individuals. Instead, both English and Shona act as a source of influence and as the students hear the Chinese words they would randomly select from either English or Shona inventory as dictated by the principle of similarity and other principles of perception.

The principle of similarity does not operate in isolation; there is also the principle of pragnanz which states that people usually simplify reality as much as possible. As observed from the above examples, the Chinese word yao[jao] which does not have any glide between the vowels [a] and [o] is simplified into the respective language which influences the learners' perception. Depending on the sound system of the language of influence, students either add glides as in [jawo] for those whose perception is influenced by Shona. In some cases there is modification of the vowel as in the variation [jea] (for English influenced students), where [ao] is intentionally modified into [ea]. In some instances, deletion also takes place as in the word 需要 [ ${ }^{\circ}$ ujao] where those students influenced by the English's sound system would delete some vowels into seeyou [si: ju:] or soya [soja]. Such changes are what Kadenge \& Mabugu (2009) in their article "The Phonological Characteristics of Shona Loanwords from English" termed related to 'rephonologization'.

Based on above principles, Zimbabwean students simplify Chinese sounds either into Shona or English. This is however by choice rather than the proximity of the sounds combined to form a word. The principle of proximity which states that elements tend to be perceived as aggregated into groups if they are near each other also played a role in shaping students' perception of Chinese sounds. When sounds are aggregated into groups they form unique sounds which differ from the individual or separate sounds. Therefore, it is possible that after combining some Chinese phonemes they end up sounding like certain Shona or English words. The above principles of perception, also supported by the wide choice of sounds from local languages led to the wide variations presented in appendix 3 .

Based on this observation we can therefore conclude that Zimbabwean students have fairly good perception of foreign sounds. This could be due to the fact that Zimbabwe is a multi-lingual country, thus Zimbabwean students easily adapt to foreign sounds. Though the impact of local languages could affect second language learners' pronunciation, however students are likely to adjust and accommodate foreign sounds easily.

\section{Conclusions}

This survey shows that in Zimbabwe, any local language at any given place can be more influential in terms of shaping students' perception towards any given target language. Based on the sample which was used for this survey, Zimbabwean students in Harare have either English influenced perception or Shona influenced perception. This means that when teaching Chinese to Zimbabweans, teachers should expect their students to have pronunciation bias which results from any of these two languages. However, results of the survey also show that there are some instances where random pattern was observed, this could be due to the uniqueness of the given Chinese sounds. This entails that in Chinese language there are certain sounds that are completely new such that Zimbabwean students will not have any clue as to how to pronounce them.

The present research has two major shortfalls; firstly the research was done in one city only, hence it is difficult to generalize these results. Secondly, the participants of the survey represent Zimbabwean population below the age of 18; it could be more interesting to carry out a similar survey with adults. The majority of students learning Chinese at the present are University students aged 19 and above. Despite these anomalies, we concluded that when teaching Chinese or any other foreign language a pre-survey is required in order to establish the prevailing influential language. Such surveys will help teachers to predict the possible pronunciation bias, hence the teachers will be able to take appropriate measures to avoid occurrence of errors.

Appendix 1. Participants of the Chinese sounds perception test

\begin{tabular}{lll}
\hline School & Age range & Number of students \\
\hline Mutasa Primary School & 11 years -14 years & 40 students \\
Glen Norah 7 Primary School & 11 years -14years & 33 students \\
Kuwangira Primary School & 10 years -12years & 44 students \\
Avondale Primary School & 9 years -12years & 42 students \\
& subtotal & $\mathbf{1 5 9}$ \\
Glen Norah 1 High School & 12 years-15 years & 47 students \\
Glen Norah 2 High School & 12 years -15 years & 38 students \\
Highfields High School & 14 years -17 years & 36 students \\
Allan Wilson High School & 13 years -17 years & 22 students \\
& subtotal & $\mathbf{1 4 3}$ \\
\hline
\end{tabular}


Appendix 2. Vocabulary for the perception test

\begin{tabular}{lllll}
\hline 1. 爸爸 baba & 6 . 特别 tebie & 11 喝 he & 16 七 qi & 21 热 re \\
2. 爬 pa & 7 哪 na & 12 猪 zhu & 17 需要 xuyao & 22 要 yao \\
3. 妈妈 mama & 8 拉 la & 13 吃饭 chifan & 18 租 zu & 23 尾 wei \\
4. 发 fa & 9 哥哥 gege & 14 谁 shei & 19 才 cai & \\
5. 大 $\mathrm{da}$ & 10 口 kou & 15 几 ji & 20 色 se & \\
\hline
\end{tabular}

Appendix 3. Spellings for Chinese words and their English and Shona variations

\begin{tabular}{|c|c|c|c|}
\hline Vocabulary used for the Survey & Spellings which are closer to English & Spellings which are closer Shona & Random spellings \\
\hline b 爸爸 baba & Papa, pahpah, pabah, parpa & Baba, pahaba, pahapa, paabha & Fafa, paraba \\
\hline $\mathrm{p}$ 爬 pa & far, faah, pahah, pha & $\mathrm{Pa}, \mathrm{ba}, \mathrm{Paa}, \mathrm{paha}$ & \\
\hline $\mathrm{m}$ 妈妈 mama & Mama, maama, marma & Mhamha, amai & mana \\
\hline $\mathrm{f}$ 发 fa & Faah, far, fair & Fa-a, fa, pfa & $\mathrm{Ba}, \mathrm{pa}$ \\
\hline $\mathrm{d}$ 大 da & Dar, daar, dah & Da, da-a, daha & bha \\
\hline $\mathrm{t}$ 特别 tebie & Turbelter, trebear, two beer, tohbiar, tedbear & Tobhiye, tobia/tubiye & keabiye \\
\hline $\mathrm{n}$ 哪 na & Nar, knee, nahar & Naha, nha, nha-a & \\
\hline 1 拉 la & La, la-a, lah, lar & & Lisa \\
\hline $\mathrm{g}$ 哥哥 gege & Google, gugul, gugoo & Gogo, gugo & gkoko \\
\hline k 口 kou & Coal, cool, koal, call & Kohu, kowu & lou \\
\hline h 喝 he & Due, cue, call & Sho, ko & Keh, chou \\
\hline zh 猪 zhu & Due, june & Ju, ju-u, chu & \\
\hline ch 吃饭 chifan & Trufan, chewfun, cheerfan, trifan & Chifani, chufani, chifana & \\
\hline sh 谁 shei & Shy, shave, share & Sheyi, shevedza, shehi & \\
\hline $\mathrm{j}$ 几 ji & Deeg, tea & Dzii, diyi, dzihi & \\
\hline$q$ 七 qi & Tea, tee, teah & Chii, tsii, si, tii & \\
\hline $\mathrm{x}$ 需要 xuyao & Soya, seeyou, suol, so young & Shuyao, shuyawo, suyawo, & Prura, tuyavo \\
\hline $\mathrm{z}$ 租 $\mathrm{zu}$ & Due, drew, draw & Dzuwu, dzu-u, dzuwa & \\
\hline c 才 cai & Tie, sar, thai, stir & Tsai, tsayi, tsvai, tsa, tsahi & $\mathrm{sac}$ \\
\hline $\mathrm{s}$ 色 se & sue, seah, sir, sew & $\mathrm{Si}, \mathrm{su}, \mathrm{sa}$ & \\
\hline $\mathrm{r}$ 热 re & Row, rew, draw & Zvo, zvoo, zhoa & Rhee, hhr \\
\hline y 要 yao & Yahoo, yea, yell, yal & Yawo, ya-a, yahu & yao \\
\hline w 尾 wei & Way, why, were & Wei, weyi, hwei, veyi & \\
\hline
\end{tabular}

Appendix 4. Average Percentages of influences

\begin{tabular}{llll}
\hline School & English influenced perception \% & Shona influenced perception \% & Other \% \\
\hline Mutasa Primary School & $39 \%$ & $57 \%$ & $4 \%$ \\
Glen Norah 7 Primary School & $37 \%$ & $55 \%$ & $8 \%$ \\
Kuwangira Primary School & $35 \%$ & $60 \%$ & $5 \%$ \\
Avondale Primary School & $43 \%$ & $48 \%$ & $9 \%$ \\
Average & $\mathbf{3 8 . 5} \%$ & $\mathbf{5 5 \%}$ & $\mathbf{6 . 5 \%}$ \\
High School & & & \\
Glen Norah 1 High School & $48 \%$ & $41 \%$ & $11 \%$ \\
Glen Norah 2 High School & $47 \%$ & $46 \%$ & $7 \%$ \\
Highfield High School & $56 \%$ & $40 \%$ & $4 \%$ \\
Allan Wilson High School & $43 \%$ & $43 \%$ & $14 \%$ \\
Average & $\mathbf{4 8 . 5 \%}$ & $\mathbf{4 2 . 5 \%}$ & $\mathbf{9 \%}$ \\
\hline
\end{tabular}

\section{References}

[1] Brown C. (1997). Acquisition of segmental structure: consequences for speech perception and second language acquisition. Unpublished Ph. D. dissertation, McGill University, Montreal, Quebec.

[2] Brown C. (2000). The interrelation between speech perception and phonological acquisition from infant to adult. In Archibald, John (ed.) Second language acquisition and linguistic theory. Oxford: Blackwell. Pp.4-63.

[3] Gong J, Cooke M \& Lecumberri MLG. (2011).Towards a quantitative model of Mandarin Chinese perception of English consonants. In Magdalena Wrembel, Malgorzata Kul and Katarzyna Dziubalska-Kolaczyk (eds.). Achievements and perspectives in SLA of speech: New Sounds. Frankfurt am Main: Peter Lang. 
[4] Hall J L. (2003). Predicting Perceptual Success with Segments: A Test of Japanese Speakers of Russian. In Juana M. Liceras et al.(ed), Proceedings of the $6^{\text {th }}$ Generative Approaches to Second Language Acquisition Conference, pp190-198. Somerville, MA: Cascadilla Proceedings Project.

[5] Fitzek, H. \& Salber, W. (1996): Gestaltpsychologie. Geschichte und Praxis. Darmstadt: Wissenschaftliche Buchgesellschaft.

[6] Fitzek, H. (2008): The Gestalt-Psychological Principles of the Concept of "Organizational Culture". Gestalt Theory, 30 (4), 487-494.

[7] Kadenge M \& Mabugu P. (2009). The Phonological Characteristics of Shona Loanwords from English. Nawa Journal of Language and Communication, 3(1). pp. 101-116.

[8] Käfer, D. (1982). Die Methodenprobleme und ihre Behandlung in Goethes Schriften zur Naturwissenschaft. Köln: Böhlau.

[9] Mayo LH, Florentine M, Buus S. (1997). Age of second-language acquisition and perception of speech in noise. Journal of speech, language, and hearing research, 40(3):686-93.

[10] Mushangwe H. (2012). Comparative Analysis of Chinese and Shona Tones. Journal of Comparative Literature and Culture, 2(2): 102-116.

[11] Mushangwe H. (2013). A Comparative Analysis of Chinese and Shona Vowels. Journal of Arts and Humanities, 2(11):77-86.
[12] Mushangwe H. (2014). Comparative analysis of the Chinese and Shona language's consonant system. Journal of Advanced Linguistic Studies, 3(1-2):118-135.

[13] Ndlovu E. (2013). Mother tongue education in official minority languages of Zimbabwe: A language management critique. Unpublished Dissertation, University of the Free State: South Africa

[14] Pajak B, Sarah C, Creel, \& Roger Levy. (2012). "Can native-language perceptual bias facilitate learning words in a new language?" In N. Miyake, D. Peebles, \& R. P. Cooper (Eds.), Proceedings of the $34^{\text {th }}$ Annual Conference of the Cognitive Science Society (pp. 2174-2179). Austin, TX: Cognitive Science Society.

[15] Sandra. (2013). Perception is reality marketing. http://www.infusefive.com/2013/04/17/perception-is-reality-m arketing/.

[16] Todorovic D. (2008). Gestalt principles. Scholarpedia, 3(12):5345.

[17] Merrian Webster Online Dictionary. (2015). Definition of Perception. http://www.merriam-webster.com/dictionary/perception.

[18] Wikipedia. (2015). Perception. http://en.wikipedia.org/wiki/Perception.

[19] Zhu L. (2014). Attention, perception, and production of the English voiceless interdental fricative by Chinese learners of English. Masters' Thesis, Michigan State University. 